\title{
Obesity induces upregulation of genes involved in myocardial $\mathrm{Ca}^{2+}$ handling
}

\author{
A.P. Lima-Leopoldo ${ }^{1}$, M.M. Sugizaki ${ }^{1}$, A.S. Leopoldo' ${ }^{1}$ R.F. Carvalho², C.R. Nogueira', \\ A.F. Nascimento ${ }^{1}$, P.F. Martinez ${ }^{1}$, R.A.M. Luvizotto ${ }^{1}$, C.R. Padovani ${ }^{3}$ and A.C. Cicogna ${ }^{1}$ \\ 1Departamento de Clínica Médica, Faculdade de Medicina de Botucatu, ${ }^{2}$ Departamento de Morfologia, \\ ${ }^{3}$ Departamento de Bioestatística, Instituto de Biociências, Universidade Estadual Paulista, Botucatu, SP, \\ Brasil
}

Correspondence to: A.P. Lima-Leopoldo, Departamento de Clínica Médica, Faculdade de Medicina de Botucatu, UNESP, Distrito de Rubião Júnior, s/n, 18618-000 Botucatu, SP, Brasil

Fax: +55-14-3811-6424. E-mail: analima@fmb.unesp.br

\begin{abstract}
Obesity is a complex multifactorial disorder that is often associated with cardiovascular diseases. Research on experimental models has suggested that cardiac dysfunction in obesity might be related to alterations in myocardial intracellular calcium $\left(\mathrm{Ca}^{2+}\right)$ handling. However, information about the expression of $\mathrm{Ca}^{2+}$-related genes that lead to this abnormality is scarce. We evaluated the effects of obesity induced by a high-fat diet in the expression of $\mathrm{Ca}^{2+}$-related genes, focusing the L-type Ca ${ }^{2+}$ channel (Cacna1c), sarcolemmal $\mathrm{Na}^{+} / \mathrm{Ca}^{2+}$ exchanger (NCX), sarcoplasmic reticulum $\mathrm{Ca}^{2+}$ ATPase (SERCA2a), ryanodine receptor (RyR2), and phospholamban (PLB) mRNA in rat myocardium. Male 30-day-old Wistar rats were fed a standard (control) or high-fat diet (obese) for 15 weeks. Obesity was defined as increased percent of body fat in carcass. The mRNA expression of $\mathrm{Ca}^{2+}$-related genes in the left ventricle was measured by RT-PCR. Compared with control rats, the obese rats had increased percent of body fat, area under the curve for glucose, and leptin and insulin plasma concentrations. Obesity also caused an increase in the levels of SERCA2a, RyR2 and PLB mRNA $(P<0.05)$ but did not modify the mRNA levels of Cacna1c and NCX. These findings show that obesity induced by high-fat diet causes cardiac upregulation of $\mathrm{Ca}^{2+}$ transport-related genes in the sarcoplasmic reticulum.
\end{abstract}

Key words: Obesity; High-fat diet; Rat heart; $\mathrm{Ca}^{2+}$ cycling; mRNA; $\mathrm{Ca}^{2+}$-related genes

Research supported by CNPq (\#130572/2005-5). Publication supported by FAPESP (\#07/53267-3).

Received November 8, 2007. Accepted July 15, 2008

\section{Introduction}

Obesity, characterized by the accumulation of excessive body fat, is considered to be a global epidemic and constitutes a major public health problem $(1,2)$. Although the etiology of obesity is complex, distinct risk factors have been implicated in its development, especially hypercaloric intake (3). Recent investigations have demonstrated that obesity decreases life expectancy and is associated with numerous medical complications, such as type 2 diabetes mellitus, dyslipidemia and cardiovascular diseases $(4,5)$.

Cardiac dysfunction has been demonstrated in an animal model of high-fat diet-induced obesity (6-8). However, the mechanisms responsible for obesity-related abnormalities in cardiac performance have not been identified. According to some investigators, functional cardiac contractile depression caused by excessive adipose tissue is related to changes in myocardial intracellular $\mathrm{Ca}^{2+}$ transients (7). Relling et al. (7), using Sprague-Dawley rats fed a high-fat diet for 12 weeks, reported that obesity-induced cardiac contractile depression is related to reduced phospholamban (PLB) phosphorylation, even though the protein expression of sarcoplasmic reticulum $\mathrm{Ca}^{2+}$ ATPase (SERCA2a) and PLB were increased.

Given the scarcity of data on the relationship between myocardial $\mathrm{Ca}^{2+}$ homeostasis and obesity, the present study evaluated the expression of L-type $\mathrm{Ca}^{2+}$ channel 
(Cacna1c), sarcolemmal $\mathrm{Na}^{+} / \mathrm{Ca}^{2+}$ exchanger (NCX), SERCA2a, ryanodine receptor (RyR2), and PLB genes in rats with high-fat diet-induced obesity.

\section{Material and Methods}

\section{Animals and experimental design}

All experiments and procedures were performed in accordance with the Guide for the Care and Use of Laboratory Animals, published by the U.S. National Institutes of Health (9) and were approved by the Botucatu Medical School Ethics Committee (UNESP, Botucatu, SP, Brazil).

Thirty-day-old male Wistar rats, provided by the Botucatu Animal Center of Botucatu Medical School, were randomly assigned to one of two groups: control ( $\mathrm{C} ; \mathrm{N}=$ 13) and obese $(\mathrm{Ob} ; \mathrm{N}=13)$. The control group was fed a standard rat chow containing $11.2 \%$ fat, $55.5 \%$ carbohydrate, and $33.3 \%$ protein; whereas the obese animals received a high-fat diet containing $45.2 \% \mathrm{kcal}$ fat, $28.6 \%$ carbohydrate, and $26.2 \%$ protein. The high-fat diet was calorically rich (high-fat diet $=4.5 \mathrm{kcal} / \mathrm{g}$ vs standard diet $=$ $3.3 \mathrm{kcal} / \mathrm{g}$ ) due to the higher fat content.

All rats were housed in individual cages in an environmentally controlled clean-air room $\left(23 \pm 3^{\circ} \mathrm{C} ; 60 \pm 5 \%\right.$ relative humidity) with a 12-h light/dark cycle (lights on at 6:00 am). Each group was fed the appropriate diet with free access to water and food for 15 consecutive weeks. Food consumption was measured daily; water intake and body weight were evaluated once a week. Weekly calorie intake was calculated by average weekly food consumption $x$ caloric value of each diet. Feed efficiency, the ability to transform calories consumed into body weight, was determined by following the formula: mean body weight gain (g) / total calorie intake. Initial and final body weight (FBW), left ventricle weight (LVW), right ventricle weight (RVW), and LVW/FBW as well as RVW/FBW ratios were calculated.

\section{Oral glucose tolerance test}

After 15 weeks of feeding, rats fasted for $12-15 \mathrm{~h}$ were submitted to oral glucose tolerance test. Blood samples were drawn from the tip of the tail at baseline and after gavage administration of a glucose load $(3 \mathrm{~g} / \mathrm{kg}$ body weight) (10). Blood samples were then collected at 0,60 , 120 , and $180 \mathrm{~min}$. Glucose levels were determined using the ACCU-CHEK GO KIT glucose analyzer (Roche Diagnostic Brazil Ltda., Brazil). Glucose tolerance was determined by the area under the curve for glucose (0-180 $\mathrm{min}$ ).

\section{Determination of plasma hormones}

At the end of the diet treatment, animals were submit- ted to a $12-15 \mathrm{~h}$ fast, anesthetized with sodium pentobarbital (50 mg/kg, intraperitoneally) and sacrificed by decapitation. Blood was collected in heparinized tubes, centrifuged at $3000 \mathrm{~g}$ for $15 \mathrm{~min}$ at $4^{\circ} \mathrm{C}$, and then stored at $-80^{\circ} \mathrm{C}$. Plasma leptin and insulin concentrations were determined by ELISA (11) using commercial kits (Linco Research Inc., USA).

\section{Body fat analysis}

After the animals were decapitated and thoracotomized, the viscera were discarded leaving only the carcass. Carcasses were dried at $100 \pm 5^{\circ} \mathrm{C}$ for $72 \mathrm{~h}$ in a ventilated Fanem ${ }^{\circledR}$ dryer (Fanem, Brazil). After drying, the carcass was wrapped in filter paper and the fat was extracted in a Soxhlet Extractor (Corning Incorporated Life Sciences, USA). The percentage of body fat in each carcass was calculated by the following formula: [(post-drying weight dry weight after fat extraction) / pre-drying weight] x 100 (12).

\section{Gene expression studies}

Cacna1c, NCX, SERCA2a, RyR2, and PLB mRNA were measured by semiquantitative RT-PCR (13). Total RNA was extracted from rat left ventricles in each experimental group using TRIzol reagent (Invitrogen, Life Technologies, Brazil), which is based on the guanidine thiocyanate method (14), according to manufacturer recommendations. Total muscle RNA (100 mg) was homogenized mechanically on ice in $1 \mathrm{~mL}$ ice-cold TRIzol reagent. RNA was solubilized in $\mathrm{RNase}$-free $\mathrm{H}_{2} \mathrm{O}$ and quantified by spectrophotometry (GeneQuant ${ }^{\mathrm{TM}}$ RNA/DNA Calculator, Amersham Pharmacia Biotech, USA) at $260 \mathrm{~nm}$. The ratio of absorbance at 260 to $280 \mathrm{~nm}$ was $>1.8$ for all samples. Degradation of RNA samples was monitored by the observation of appropriate $28 \mathrm{~S}$ to $18 \mathrm{~S}$ ribosomal RNA ratios as determined by ethidium bromide staining of the agarose gels. One microliter of RNA (1000 $\mathrm{ng} / \mu \mathrm{L}$ ) was reverse transcribed with random hexamer primers and Superscript II RT, according to standard methods (Invitrogen). Negative control RT reactions were carried out in which the RT enzyme was omitted. The negative control RT reactions were PCR amplified to ensure that DNA did not contaminate RNA. The cDNA $(1.5 \mu \mathrm{L})$ was then amplified using 10 $\mu \mathrm{M}$ of each primer, 10X PCR buffer, DEPC water, $50 \mathrm{mM}$ $\mathrm{MgCl}_{2}, 10 \mathrm{mM}$ dNTPs and 2 units Taq polymerase ${ }^{\circledR}$ (Invitrogen) in a final volume of $25 \mu \mathrm{L}$. Transcript levels for the constitutive housekeeping gene product cyclophilin were measured in each sample and used to normalize the transcript data obtained. The data were expressed as change relative to control values.

The primer sequences used were: PLB: S 5'TACC 
TTACTCGCTCGGCTATC3' and AS 5'CAGAAGCATCA CAATGATGCAG3'; SERCA2a: S 5'ATGAGATCACAGCT ATGACTGGTG3' and AS 5'GCATTGCACATCTCTAT GGTGACTAG 3'; RYR2: S 5'GAATCAGTGAGTTACT GGGCATGG3' and AS 5'CTGGTCTCTGAGTTCTC CAAAAGC3', and cyclophilin: S 5'ACGCCGCTGTCT CTTTTC3' and AS 5'TGCCTTCTTTCACCTTCC3' as proposed by Mirit et al. (15) and Coussin et al. (16). Primer pairs for Cacna1c, and NCX were determined using the Primer 3 software available on-line at http://frodo.wi.mit.edu/ cgi-bin/primer3/primer3_www.cgi. To determine specificity, sequences were compared with GenBank using the Blast program available at the National Central Biotechnology Information website (http://www.ncbi.nlm.nih.gov/). The following primers were used: Cacna1c: S 5'TCTGCTCTG CCTGACTCTGA3' and AS 5'GAGATACTCCACCC GTTCCA3'; NCX: S 5'GGCAGAAACAGGAGGAAATG3' and AS 5'AGCGGACACAACACAGATGG3'. Preliminary experiments were conducted with each gene product to determine the number of PCR cycles that provided a linear range of amplification. cDNA from each sample for both the control and obese groups was amplified simultaneously using aliquots from the same PCR mixture. After PCR amplification, $10 \mu \mathrm{L}$ of each reaction was electrophoresed on $1 \%$ agarose gels stained with ethidium bromide. Images were captured and bands corresponding to each gene were quantified by densitometry by the Labworks ${ }^{\mathrm{TM}}$ Analysis Software 3.0 (UV/White Darkroom, UVP Laboratory Products, USA). PCR products were run in triplicate on gels different for each gene and results were averaged. The size (number of base pairs) of each band corresponds to the size of processed mRNA. The target genes were normalized to housekeeping gene cyclophilin (17).

\section{Statistical analysis}

Data are reported as means \pm standard deviation. Comparisons between groups were performed using the Student $t$-test for independent samples. The mean weekly body weight and the glucose profile of the groups were compared by ANOVA for repeated measures. When significant differences were found $(P<0.05)$, the post hoc Bonferroni multiple comparisons test was carried out (18). The level of significance was considered to be $5 \%$.

\section{Results}

The control and obese groups started with similar body weight at week 0 of the study. However, a significant difference in body weight between the groups was observed at week 2 and thereafter (Figure 1). Table 1 shows the influence of obesity on the general and nutritional characteristics of the animals. Although the obese group ingested less food than the control group, the calorie intake, feed efficiency, and final body weights of the obese rats after 15 weeks were greater than the control rats by approximately $23 \%$. Furthermore, the percentage of carcass body fat was markedly higher for the obese group ( $\mathrm{C}$ $=9 \pm 1$ vs $\mathrm{Ob}=17 \pm 7 \%, \mathrm{P}<0.05)$. Water consumption was similar for both groups. LVW and RVW were higher in obese animals than in controls, but no statistical difference

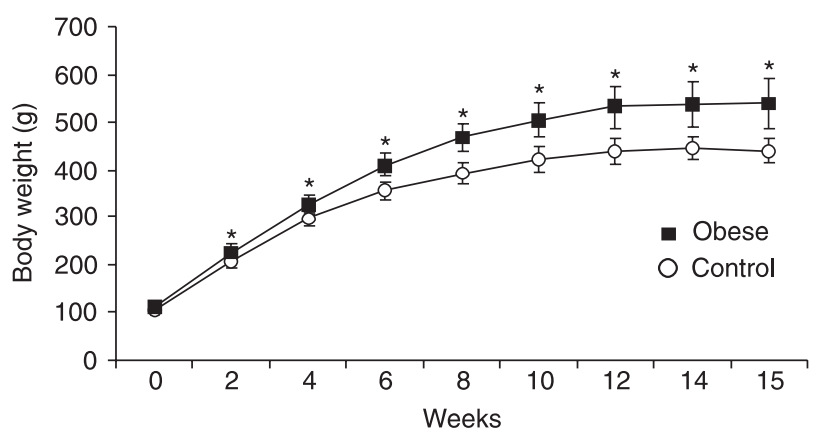

Figure 1. Weekly body weight control of obese and control rats. Data are reported as means \pm SD for 13 rats in each group. ${ }^{*} \mathrm{P}<$ 0.05 vs control (ANOVA for repeated measures and post hoc Bonferroni test).

Table 1. Effect of high-fat diet-induced obesity on the general and nutritional characteristics of rats.

\begin{tabular}{|c|c|c|}
\hline Characteristics & Control $(N=13)$ & Obese $(N=13)$ \\
\hline IBW (g) & $106 \pm 10$ & $111 \pm 10$ \\
\hline FBW (g) & $439 \pm 26$ & $539 \pm 52^{*}$ \\
\hline LVW (g) & $0.85 \pm 0.09$ & $0.99 \pm 0.09^{*}$ \\
\hline $\operatorname{RVW}(g)$ & $0.22 \pm 0.03$ & $0.28 \pm 0.04^{*}$ \\
\hline LVW/FBW (mg/g) & $1.93 \pm 0.20$ & $1.84 \pm 0.19$ \\
\hline RVW/FBW (mg/g) & $0.52 \pm 0.03$ & $0.52 \pm 0.04$ \\
\hline FC (g/day) & $22.2 \pm 1.2$ & $16.4 \pm 1.4^{*}$ \\
\hline WC (mL/day) & $40.9 \pm 4.7$ & $41.8 \pm 3.7$ \\
\hline $\mathrm{Cl}\left(\mathrm{g} \cdot \mathrm{kcal}^{-1} \cdot \mathrm{day}^{-1}\right)$ & $73.2 \pm 3.8$ & $85.2 \pm 6.7^{*}$ \\
\hline FE (g/kcal) & $0.043 \pm 0.002$ & $0.048 \pm 0.003^{*}$ \\
\hline FAT $(\%)$ & $9 \pm 1$ & $17 \pm 7^{*}$ \\
\hline$A \cup C$ & $20247.7 \pm 1416.8$ & $23596.2 \pm 3023.4^{*}$ \\
\hline
\end{tabular}

Male rats received a high-fat diet $(45.2 \%$ fat, $28.6 \%$ carbohydrate) and controls received a standard diet (11.2\% fat and $55 \%$ carbohydrate) for 15 weeks. Data are reported as mean \pm SD. IBW = initial body weight; FBW = final body weight; LVW = left ventricle weight; RVW = right ventricle weight; $L V W / F B W=$ left ventricle and final body weight ratio; RVW/FBW = right ventricle and final body weight ratio; $\mathrm{FC}=$ food consumption; $\mathrm{WC}=$ water consumption; $\mathrm{Cl}=$ calorie intake; $\mathrm{FE}=$ feed efficiency; $\mathrm{FAT}(\%)=$ percent of body fat in carcass; AUC = area under the curve for glucose. ${ }^{*} \mathrm{P}<0.05$ vs control (Student $t$-test for independent samples). 
between groups was observed after normalization to FBW (Table 1).

The area under the curve for glucose $(C=20247.7 \pm$ 1416.8 vs $\mathrm{Ob}=23596.2 \pm 3023.4 ; \mathrm{P}<0.05)($ Table 1$)$, plasma leptin $(\mathrm{C}=2.31 \pm 0.53$ vs $\mathrm{Ob}=4.82 \pm 1.34 ; \mathrm{P}<$ $0.05)$ and insulin levels $(C=0.45 \pm 0.19$ vs $\mathrm{Ob}=1.48 \pm$ 0.67 ; $P<0.05)$ were higher in the obese group than in the control group, which indicates that the obese rats were hyperinsulinemic, hyperleptinemic and glucose intolerant.

The measurement of gene expression by RT-PCR revealed that the cardiac mRNA expression of SERCA2a, PLB and RyR2 was enhanced in the obese group ( $C=1.00$ \pm 0.11 vs $\mathrm{Ob}=1.18 \pm 0.17, \mathrm{P}<0.05 ; \mathrm{C}=1.00 \pm 0.05$ vs Ob

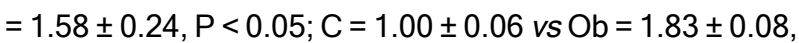
$\mathrm{P}<0.05$, respectively). However, Cacna1c and NCX mRNA levels were not different $(C=1.00 \pm 0.10$ vs $\mathrm{Ob}=1.03 \pm$ $0.08, \mathrm{C}=1.00 \pm 0.05$ vs $\mathrm{Ob}=1.01 \pm 0.04, \mathrm{P}>0.05$, respectively; Figure 2).

\section{Discussion}

The results of the present study show that rats fed a high-fat diet for 15 weeks had a $22.8 \%$ increase in final body weight and an $89 \%$ increase in body fat compared with control animals. The difference in body weight between groups was observed after two weeks of obesity induction (Figure 1). Although the obese group ingested less food, the higher weight gain exhibited by these animals was most likely due to their increased calorie intake and feed efficiency. In addition, the obese rats developed metabolic abnormalities that are typically associated with obesity, e.g., glucose intolerance, hyperinsulinemia and hyperleptinemia. These findings are consistent with other studies that have reported that diet-induced obesity displays several characteristics commonly related to human and experimental obesity $(7,19)$.

Our major findings suggest that obesity induced the

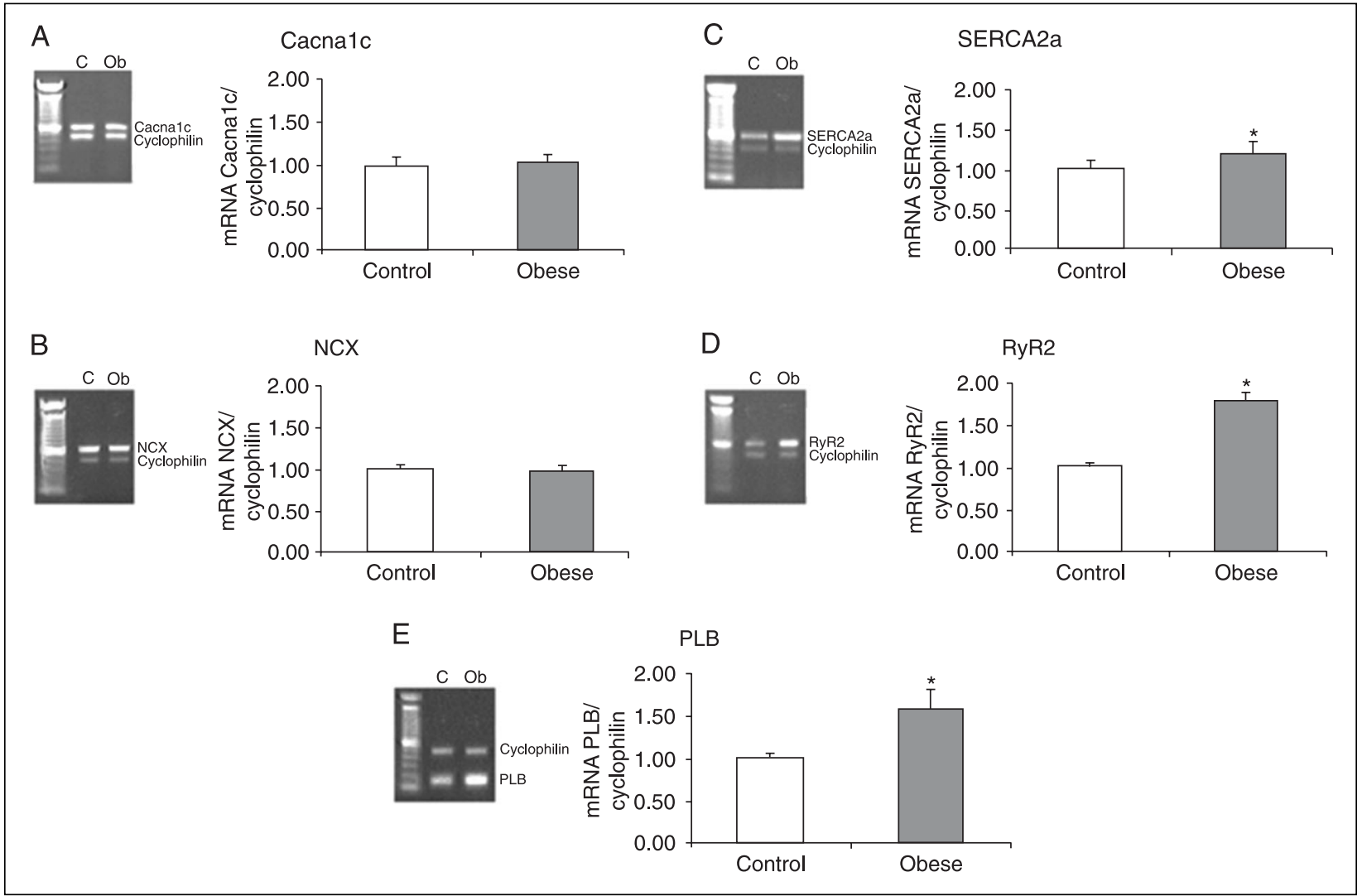

Figure 2. Effect of high-fat diet-induced obesity on the expression of genes related to $\mathrm{Ca}^{2+}$ transport in the rat. RT-PCR was carried out for L-type $\mathrm{Ca}^{2+}$ channel (Cacna1c; 604 bp, 28 cycles), $\mathrm{Na}^{+} / \mathrm{Ca}^{2+}$ exchanger (NCX; 634 bp, 28 cycles), Ca ${ }^{2+}$ ATPase (SERCA2a; $653 \mathrm{bp}, 28$ cycles), ryanodine receptor (RyR2; $635 \mathrm{bp}, 28 \mathrm{cycles}$ ), and phospholamban (PLB; $140 \mathrm{bp}, 30$ cycles). Gene expression was normalized to cyclophilin expression (440 bp). Experiments on control $(C, N=13)$ and obese $(\mathrm{Ob}, N=13)$ rats were performed in triplicate and PCR quantification was by densitometry analysis. ${ }^{*} \mathrm{P}<0.05 \mathrm{vs}$ control (Student $t$-test for independent samples). 
upregulation of the gene expression of proteins related to $\mathrm{Ca}^{2+}$ transport, SERCA2a, RyR2 and PLB, but did not cause changes in sarcolemmal $\mathrm{Ca}^{2+}$ genes, NCX and Cacna1c. This result confirms Relling et al. (7) who reported enhanced protein expression of SERCA2a and PLB in obese rats. These investigators have suggested that the increased protein expression of SERCA2a may reflect a compensatory mechanism to restore impaired intracellular $\mathrm{Ca}^{2+}$ handling. On the other hand, other investigators have observed unchanged SERCA2a, RyR2 and PLB protein expression levels in non-obese rats fed a high-fat diet (6). This result could indicate that only a highfat diet without obesity does not affect expression of $\mathrm{Ca}^{2+}$ related genes.

The mechanisms responsible for changes in transcriptional factors that regulate the expression of $\mathrm{Ca}^{2+}$-related genes in obesity are still unknown. Given that most studies on obesity report increased triiodothyronine levels (T3) $(20-22)$, and that this hormone is related to SERCA2a expression $(23,24)$, the T3 elevation may be responsible for the increase in SERCA2a mRNA. However, since obe- sity has been associated with elevated insulin, leptin, cytokines, endothelin and renin, angiotensin and aldosterone levels, as well as sympathetic nerve activity $(19,25-$ 30 ), which stimulate different transcriptional signaling pathways, it is possible that one or more of these factors may be involved in the overexpression of the SERCA2a, RyR2 and PLB.

Our findings showed that obesity induced by high-fat diet causes cardiac upregulation of $\mathrm{Ca}^{2+}$ transport-related genes in the sarcoplasmic reticulum. Further studies are necessary to determine if changes in the mRNA expression are accompanied by alterations of protein expression and the mechanisms responsible for changes in myocardial $\mathrm{Ca}^{2+}$-related genes in obese rats.

\section{Acknowledgments}

We are grateful to José Georgette, Mário Bruno, Sandra Fábio, Elenize Pereira, Sueli Clara, Vitor Souza, José Aparecido, Rogério Monteiro, Antônio de Lalla, Camila Camacho, and Corina Corrêa for their technical assistance and GAP (group to support research) for revising the English text.

\section{References}

1. Eckel RH, Barouch WW, Ershow AG. Report of the National Heart, Lung, and Blood Institute - National Institute of Diabetes and Digestive and Kidney Diseases Working Group on the pathophysiology of obesity-associated cardiovascular disease. Circulation 2002; 105: 2923-2928.

2. O'Brien PE, Dixon JB. The extent of the problem of obesity. Am J Surg 2002; 184: 4S-8S.

3. Stein CJ, Colditz GA. The epidemic of obesity. J Clin Endocrinol Metab 2004; 89: 2522-2525.

4. Malnick SD, Knobler $\mathrm{H}$. The medical complications of obesity. QJM 2006; 99: 565-579.

5. Poirier P, Giles TD, Bray GA, Hong $Y$, Stern JS, Pi-Sunyer FX, et al. Obesity and cardiovascular disease: pathophysiology, evaluation, and effect of weight loss: an update of the 1997 American Heart Association Scientific Statement on Obesity and Heart Disease from the Obesity Committee of the Council on Nutrition, Physical Activity, and Metabolism. Circulation 2006; 113: 898-918.

6. Ouwens DM, Boer C, Fodor M, de Galan P, Heine RJ, Maassen JA, et al. Cardiac dysfunction induced by high-fat diet is associated with altered myocardial insulin signalling in rats. Diabetologia 2005; 48: 1229-1237.

7. Relling DP, Esberg LB, Fang CX, Johnson WT, Murphy EJ, Carlson EC, et al. High-fat diet-induced juvenile obesity leads to cardiomyocyte dysfunction and upregulation of Foxo3a transcription factor independent of lipotoxicity and apoptosis. J Hypertens 2006; 24: 549-561.

8. Ouwens DM, Diamant M, Fodor M, Habets DD, Pelsers MM, El Hasnaoui M, et al. Cardiac contractile dysfunction in insulin-resistant rats fed a high-fat diet is associated with elevated CD36-mediated fatty acid uptake and esterification. Diabetologia 2007; 50: 1938-1948.

9. Committee on Care and Use of Laboratory Animals. Guide for the care and use of laboratory animals. Bethesda: National Institute of Health; 1985.

10. Borst SE, Conover CF. High-fat diet induces increased tissue expression of TNF-alpha. Life Sci 2005; 77: 21562165.

11. Okere IC, Chandler MP, McElfresh TA, Rennison JH, Sharov V, Sabbah HN, et al. Differential effects of saturated and unsaturated fatty acid diets on cardiomyocyte apoptosis, adipose distribution, and serum leptin. Am J Physiol Heart Circ Physiol 2006; 291: H38-H44.

12. Woods SC, Seeley RJ, Rushing PA, D'Alessio D, Tso P. A controlled high-fat diet induces an obese syndrome in rats. J Nutr 2003; 133: 1081-1087.

13. Vizotto VA, Carvalho RF, Sugizaki MM, Lima AP, Aragon FF, Padovani CR, et al. Down-regulation of the cardiac sarcoplasmic reticulum ryanodine channel in severely foodrestricted rats. Braz J Med Biol Res 2007; 40: 27-31.

14. Chomczynski $P$, Sacchi N. Single-step method of RNA isolation by acid guanidinium thiocyanate-phenol-chloroform extraction. Anal Biochem 1987; 162: 156-159.

15. Mirit E, Palmon A, Hasin Y, Horowitz M. Heat acclimation induces changes in cardiac mechanical performance: the role of thyroid hormone. Am J Physiol 1999; 276: R550R558.

16. Coussin F, Macrez N, Morel JL, Mironneau J. Requirement 
of ryanodine receptor subtypes 1 and 2 for $\mathrm{Ca}(2+)$-induced $\mathrm{Ca}(2+)$ release in vascular myocytes. $J$ Biol Chem 2000; 275: 9596-9603.

17. Alway SE, Degens H, Lowe DA, Krishnamurthy G. Increased myogenic repressor Id mRNA and protein levels in hindlimb muscles of aged rats. Am J Physiol Regul Integr Comp Physiol 2002; 282: R411-R422.

18. Bayley BJR. Tables of the Bonferroni "t" statistic. J Am Stat Assoc 1977; 72: 469-478.

19. Barnes MJ, Lapanowski K, Conley A, Rafols JA, Jen KL, Dunbar JC. High fat feeding is associated with increased blood pressure, sympathetic nerve activity and hypothalamic mu opioid receptors. Brain Res Bull 2003; 61: 511-519.

20. Kokkoris $\mathrm{P}, \mathrm{Pi}$-Sunyer $\mathrm{FX}$. Obesity and endocrine disease. Endocrinol Metab Clin North Am 2003; 32: 895-914.

21. Michalaki MA, Vagenakis AG, Leonardou AS, Argentou MN, Habeos IG, Makri MG, et al. Thyroid function in humans with morbid obesity. Thyroid 2006; 16: 73-78.

22. Reinehr T, Andler W. Thyroid hormones before and after weight loss in obesity. Arch Dis Child 2002; 87: 320-323.

23. Rohrer D, Dillmann WH. Thyroid hormone markedly increases the mRNA coding for sarcoplasmic reticulum $\mathrm{Ca}^{2+}$
ATPase in the rat heart. $J$ Biol Chem 1988; 263: 6941-6944.

24. Baker DL, Hashimoto K, Grupp IL, Ji Y, Reed T, Loukianov $\mathrm{E}$, et al. Targeted overexpression of the sarcoplasmic reticulum $\mathrm{Ca}^{2+}$-ATPase increases cardiac contractility in transgenic mouse hearts. Circ Res 1998; 83: 1205-1214.

25. Rondinone CM. Adipocyte-derived hormones, cytokines, and mediators. Endocrine 2006; 29: 81-90.

26. Kershaw EE, Flier JS. Adipose tissue as an endocrine organ. J Clin Endocrinol Metab 2004; 89: 2548-2556.

27. Adiarto S, Emoto N, Iwasa N, Yokoyama M. Obesity-induced upregulation of myocardial endothelin-1 expression is mediated by leptin. Biochem Biophys Res Commun 2007; 353: 623-627.

28. Pausova Z. From big fat cells to high blood pressure: a pathway to obesity-associated hypertension. Curr Opin Nephrol Hypertens 2006; 15: 173-178.

29. Rocchini AP. Obesity hypertension. Am J Hypertens 2002; 15: $50 \mathrm{~S}-52 \mathrm{~S}$.

30. Rahmouni K, Correia ML, Haynes WG, Mark AL. Obesityassociated hypertension: new insights into mechanisms. Hypertension 2005; 45: 9-14. 